\title{
Copper 64 Cu-DOTA-daratumumab
}

National Cancer Institute

\section{Source}

National Cancer Institute. Copper 64 Cu-DOTA-daratumumab. NCI Thesaurus. Code C140353.

A radioimmunoconjug ate containing daratumumab, a human immunog lobulin G1 kappa (IgG1k) monoclonal antibody directed against the cell surface glycoprotein CD38, conjug ated with the bifunctional, macrocyclic chelating agent tetraazacyclododecanetetra-acetic acid (DOTA), and labeled with the radioisotope copper Cu 64 , with potential diagnostic properties upon positron emission tomography (PET) imaging. The monoclonal antibody moiety of copper Cu 64-DOTA-daratumumab specifically targets and binds to cell surface antigen CD38. Upon binding, the radioisotope moiety may be detected using PET, thereby allowing the imaging and quantification of CD38-expressing tumor cells. CD38, a cell surface glycoprotein, is expressed on various hematopoietic cells and is overexpressed on multiple myeloma (MM) cells. 